\title{
APLICAÇÃO DE FRICTION STIR WELDING (FSW) NA UNIÃO DE CHAPAS FINAS DE ALUMÍNIO*
}

Fábio Luiz dos Santos ${ }^{1}$ Fernando Dellacqua Cristo ${ }^{2}$ Miguel Borodiak ${ }^{3}$

\section{Resumo}

As ligas de alumínio, em particular, apresentam certas restrições quando submetidas ao processo de união por soldagem. Isto se deve, principalmente, por apresentarem elevada condutividade térmica, elevada contração na solidificação e elevada solubilidade de hidrogênio. Levando em conta estes aspectos, o processo de soldagem FSW apresenta grande potencial para esta aplicação, visto que, é autógena, realizada sem fusão do material e sem utilização de escórias ou gases de proteção. A partir deste conceito, o objetivo do presente trabalho é avaliar a união de chapas finas de alumínio da liga $3105 \mathrm{H} 26$, com espessura de 0,7mm. Para realização dos testes, foram analisados fatores como: penetração da ferramenta nas chapas processadas, ângulo de ataque, tipo de ferramenta e modo de controle de penetração (posição ou força). Os resultados indicaram que o modo de controle por força se mostrou o mais indicado para chapas finas, e que o regime transiente no início de soldagem foi a parte mais crítica para controle da qualidade da junta soldada.

Palavras-chave: Soldagem FSW; Alumínio; Chapas; 3105 H26.

\section{THE USE OF FSW IN THINNER ALUMINIUM SHEETS}

\begin{abstract}
Aluminium alloys in particular, have certain limitations when subjected to welding bonding process. This is mainly present with a high thermal conductivity, high contraction in solidification and high solubility of hydrogen. Taking this into account, the welding process FSW has great potential for this application, since it is autogenous held without melting the material and without the use of slag or shielding gases. From this concept, the aim of this study is to evaluate the joining of thin sheets of aluminum alloy $3105 \mathrm{H} 26$ with a thickness of $0.7 \mathrm{~mm}$. To perform the test, factors were analyzed as of the tool in processed plates, angle of attack, type of tool penetration and control mode (position or force). The results indicate that the control mode is shown under the most suitable for thin slabs, and that the transient at the beginning of welding is the most critical part to control the weld quality.
\end{abstract}

Keywords: Welding FSW; Aluminium; Sheets; 3105 H26.

1 Engenheiro de Produção Mecânica, Eng. de P\&D, Gerência de Tecnologia de Fundição e Transformação Plástica, Votorantim Metais-Companhia Brasileira de Alumínio I, Alumínio, SP, Brasil.

2 Engenheiro Metalurgista, Trainee Programa Inova Talentos-CNPq/IEL, Gerência de Tecnologia de Fundição e Transformação Plástica, Votorantim Metais-Companhia Brasileira de Alumínio, Alumínio, SP, Brasil.

3 Bacharel em Química, Técnico Metalógrafo, Laboratório Químico, Votorantim Metais-Companhia Brasileira de Alumínio, Alumínio, SP, Brasil. 


\section{INTRODUÇÃO}

O processo de soldagem FSW (Friction Stir Welding) é uma variante dos processos de soldagem no estado sólido (SSW). Este processo, desenvolvido e patenteado por Thomas Wayne em 1991, no TWI (The Welding Institute), consiste na união de materiais através da aglomeração mecânica por atrito das partes as serem unidas. Estas por sua vez, são atritadas por um pino em rotação, acoplado a uma ferramenta não consumível que no decorrer do processo, promove a geração de calor que facilitará o escoamento de material (fluxo plástico) no deslocamento da ferramenta sobre a peça [1]. O resultado desta ação é a formação de uma união (cordão de solda) cuja resistência chega a ser de 30 a $50 \%$ maior que a soldagem por arco elétrico [2]. Porém, devido as características do processo, o fluxo plástico do material envolve complexos mecanismos de deformação durante a formação da junta. A medida que se tem ao avanço da ferramenta, forças trativas são exercidas na frente de processo enquanto que, na parte anterior a ferramenta, forças compressivas são dominantes. Além disso, a rotação do pino e a direção de solda são as mesmas para a região de início de deformação da junta (AS - Advancing Side) e opostas na região de redistribuição do metal (RS - Retreating Side), originando uma junta assimétrica, cujas propriedades vão depender da geometria da ferramenta, velocidade de soldagem, penetração, dentre outras variáveis [3]. Na Figura 1 tem-se uma visão geral do processo FSW, assim como alguns aspectos da formação da junta citados acima.

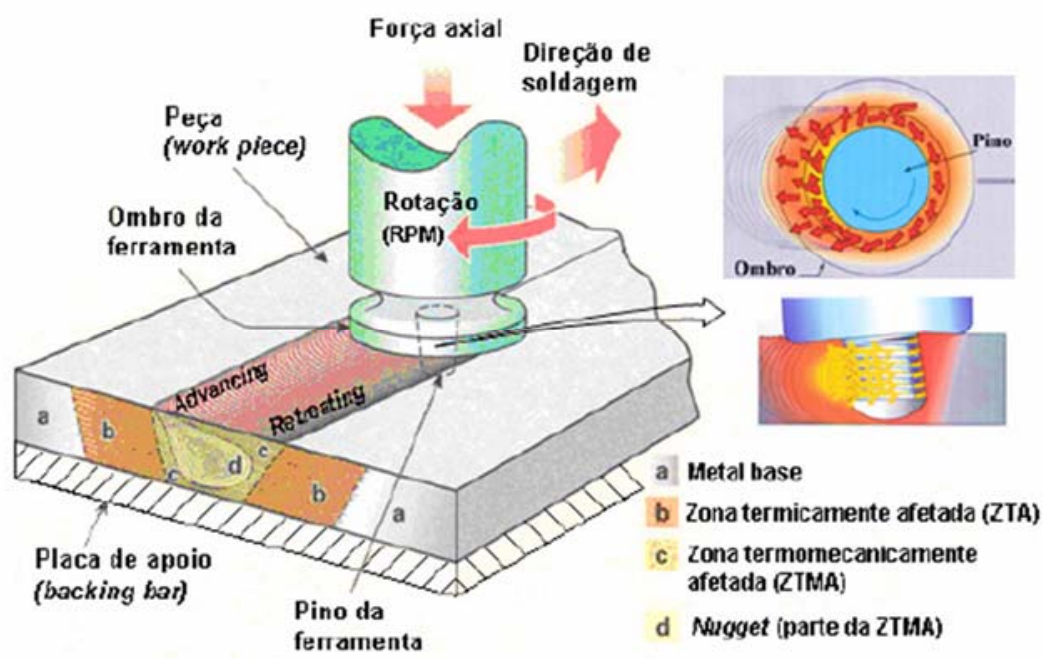

Figura 1. Representação do processo de soldagem FSW [2].

A assimetria entre os lados da junta formada pode então afetar a microestrutura da região, a Zona Termicamente Afetada (ZTA) e também a Zona Termomecanicamente Afetada (ZTMA), os quais estão diretamente relacionadas com a integridade da união soldada [3-4].

Desta maneira, neste trabalho foi verificado a influência de parâmetros operacionais como penetração da ferramenta, ângulo de ataque, tipo de ferramenta e modo de controle de penetração (posição ou força), na realização de juntas soldadas topo a topo de chapas de alumínio da liga 3105 H26. Além da dificuldade em soldar ligas de alumínio tratáveis termicamente, este trabalho ainda aborda o desafio tecnológico de soldar chapas com pequena espessura, neste caso, com apenas $0,7 \mathrm{~mm}$. 


\section{MATERIAIS E MÉTODOS}

Os testes foram realizados em uma máquina de soldagem FSW disponível no IPTLEL com as seguintes características:

- Fabricante e modelo: MTI - GG-7-2.0;

- Relatório Técnico n 142 374-205 2/25

- Comando CNC de 5 eixos de movimentação (além de eixos auxiliares de processo);

- Modos de controle: posição e força;

- Capacidade máxima de força axial: $80 \mathrm{kN}$;

- Velocidade de avanço máxima: $6000 \mathrm{~mm} / \mathrm{min}$;

- Volume de trabalho aproximado (X, Y, Z): $2 \mathrm{~m} \times 2,4 \mathrm{~m} \times 0,9 \mathrm{~m}$

A metodologia e configuração dos testes de soldagem estão descritas na Tabela 1, e os parâmetros especificados nos itens $2.1,2.2,2.3$.

\subsection{Dispositivos de Fixação de Chapas e Configurações de Soldagem}

Foi utilizado um dispositivo de fixação de chapas disponível no IPT, constituído por pinças de fixação mecânica por parafusos e chapa de apoio (backing plate) substituível, como indica a Figura 2.

No decorrer dos testes, foram desenvolvidas e testadas as configurações de soldagem listadas a seguir:

- Configuração 1: uma chapa (penetração no material, sem soldagem);

- Configuração 2: duas chapas sobrepostas;

- Configuração 3: duas chapas em topo com tira sobreposta sobre as chapas;

- Configuração 4: duas chapas em topo com tira sobreposta sob as chapas.

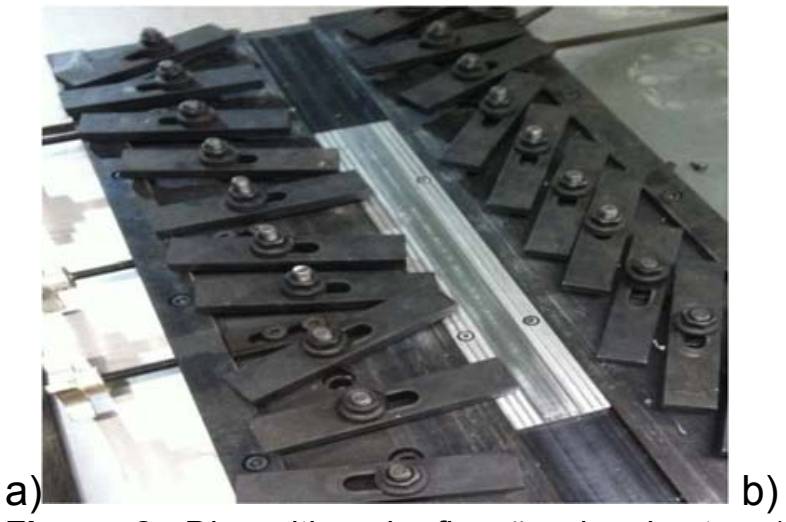

\section{IIIIIIIII

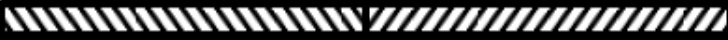

Configuração 3: duas chapas em topo, com tira sobre essas

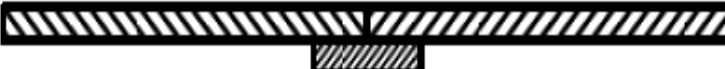

Configuração 4: duas chapas em topo, com tira sob essas

Figura 2. Dispositivo de fixação das hastes (a) e configurações 3 e 4 de soldagem melhor detalhadas (b).

\subsection{Ferramentas de Soldagem}

Para execução dos testes, foram utilizadas as seguintes ferramentas de soldagem:

- Ferramenta 1: ombro de $8 \mathrm{~mm}$ de diâmetro, pino cilíndrico liso de 0,6 mm de comprimento (fornecimento Votorantim Metais);

- Ferramenta 2: ombro de $10 \mathrm{~mm}$ de diâmetro (ranhura em espiral), pino cilíndrico facetado (disponível no IPT, MTI 015701);

- Ferramenta 3: ombro de $8 \mathrm{~mm}$ de diâmetro, pino cilíndrico liso de 1,3 mm de comprimento (fornecimento Votorantim Metais);

- Ferramenta 4: ombro de $8 \mathrm{~mm}$ de diâmetro, pino cônico liso de 1,3 $\mathrm{mm}$ de comprimento (fornecimento Votorantim Metais). 
Tabela 1. Metodologia e configuração dos testes de soldagem.

\begin{tabular}{|c|c|c|c|c|c|c|c|c|c|}
\hline & Configuração & $\begin{array}{l}\text { Ferra } \\
\text { menta }\end{array}$ & $\begin{array}{l}\text { Rotação } \\
\text { [rpm] }\end{array}$ & $\begin{array}{l}\text { Avanço } \\
\text { [mm/mi } \\
\text { n] }\end{array}$ & $\begin{array}{l}\text { Ângulo } \\
\text { de } \\
\text { Ataque } \\
\left.{ }^{\circ}\right]\end{array}$ & $\begin{array}{l}\text { Modo de } \\
\text { Controle }\end{array}$ & $\begin{array}{l}\text { Penetração } \\
\text { [mm] }\end{array}$ & $\begin{array}{l}\text { Força } \\
{[\mathrm{N}]}\end{array}$ & $\begin{array}{l}\text { Penetração } \\
\text { Limite } \\
\text { [mm] }\end{array}$ \\
\hline Teste 01 & 1 & 1 & 700 & 240 & $-3,0$ & Posição & $-0,65$ & - & $-0,70$ \\
\hline Teste 02 & 1 & 1 & 700 & 240 & $-3,0$ & Posição & $-0,65$ & - & $-0,70$ \\
\hline Teste 03 & 1 & 1 & 700 & 240 & $-3,0$ & Posição & $-0,65$ & - & $-0,70$ \\
\hline Teste 04 & 1 & 1 & 700 & 240 & $-1,0$ & Posição & $-0,65$ & - & $-0,70$ \\
\hline Teste 05 & 1 & 1 & 700 & 240 & $-1,0$ & Posição & $-0,65$ & - & $-0,70$ \\
\hline Teste 06 & 2 & 2 & 1600 & 240 & $-3,0$ & Posição & $-0,80$ & - & $-0,90$ \\
\hline Teste 07 & 2 & 2 & 1600 & 240 & $-3,0$ & Posição & $-0,76$ & - & $-0,90$ \\
\hline Teste 08 & 2 & 2 & 1600 & 240 & $-3,0$ & Posição & $-0,73$ & - & $-0,90$ \\
\hline Teste 09 & 2 & 2 & 1600 & 240 & $-1,0$ & Posição & $-0,73$ & - & $-0,90$ \\
\hline Teste 10 & 2 & 2 & 1200 & 240 & $-1,0$ & Posição & $-0,73$ & - & $-0,90$ \\
\hline Teste 11 & 2 & 2 & 1200 & 300 & $-1,0$ & Posição & $-0,73$ & - & $-0,90$ \\
\hline Teste 12 & 2 & 2 & 1200 & 400 & $-1,0$ & Posição & $-0,73$ & - & $-0,90$ \\
\hline Teste 13 & 3 & 2 & 1200 & 500 & $-1,0$ & Posição & $-0,73$ & - & $-0,90$ \\
\hline Teste 14 & 3 & 2 & 1200 & 400 & $-1,0$ & Posição & $-0,73$ & - & $-0,90$ \\
\hline Teste 15 & 3 & 2 & 1200 & 400 & $-1,0$ & Posição & $-0,73$ & - & $-0,90$ \\
\hline Teste 16 & 3 & 2 & 1200 & 400 & $-1,0$ & Força & - & 2300 & $-0,75$ \\
\hline Teste 17 & 3 & 2 & 1200 & 400 & $-1,0$ & Força & - & 2300 & $-0,75$ \\
\hline Teste 18 & 4 & 3 & 1200 & 400 & $-1,0$ & Força & - & 2300 & $-1,35$ \\
\hline Teste 19 & 4 & 3 & 1300 & 400 & $-1,0$ & Força & - & 1100 & $-1,35$ \\
\hline Teste 20 & 4 & 3 & 1400 & 400 & $-1,0$ & Força & - & 1100 & $-1,35$ \\
\hline Teste 21* & 4 & 3 & 1400 & 400 & $-1,0$ & Força & - & 1000 & $-1,35$ \\
\hline Teste 22 & 4 & 4 & 1400 & 400 & $-1,0$ & Força & - & 1000 & $-1,35$ \\
\hline Teste 23 & 4 & 4 & 800 & 400 & $-1,0$ & Força & - & 2200 & $-1,35$ \\
\hline Teste 24 & 4 & 4 & 1400 & 400 & $-1,0$ & Força & - & 1200 & $-1,35$ \\
\hline Teste 25 & 4 & 4 & 1400 & 400 & $-1,0$ & Força & - & 1200 & $-1,30$ \\
\hline Teste 26 & 4 & 4 & 1400 & 400 & $-1,0$ & Força & - & 1200 & $-1,30$ \\
\hline
\end{tabular}

*Teste 21 foi abortado no início de sua execução, pois houve penetração excessiva da ferramenta nas chapas a serem soldadas. Assim, os parâmetros do Teste 22, são idênticos aos do Teste 21 (exceto pelo perfil da ferramenta de soldagem).

\subsection{Material Processado}

Todas as chapas utilizadas nos testes foram obtidas por laminação, com 0,7 mm de espessura, empregando-se a liga de alumínio 3105 H26. Todos os testes foram realizados com a direção de soldagem igual a direção de laminação.

Entretanto, as primeiras amostras (utilizadas nos Testes 1 a 17, e no Teste 26) possuíam acabamento e irregularidades geométricas de suas bordas de acordo com seus processos de corte, por serra de fita. Já a segunda parte das amostras (utilizadas nos testes 18 a 25), foi fresada com a finalidade de se aprimorar suas características geométricas.

\section{RESULTADOS E DISCUSSÃO}

Os resultados obtidos a partir dos testes listados na Tabela 1 serão discutidos a seguir, enfatizando os efeitos realizados, a cada mudança de configuração, a partir da estabilidade do processo (penetração e força axial) e aspecto visual da união soldada.

No primeiro teste realizado, utilizando-se a configuração 1 (chapa simples, sem soldagem) e a ferramenta 1 (pino cilíndrico liso de 0,6 $\mathrm{mm}$ de comprimento), ocorreu o rompimento da chapa por quase toda a extensão do percurso da ferramenta, 
exceto pelo trecho final, como pode ser observado na Figura 3. Observa-se que o controle de posição seguiu corretamente o parâmetro de penetração especificado. Já a medição da força axial, só pode ser considerada válida no trecho final, em que houve estabilidade do processo. Nesse trecho, a força flutuou em torno de $2300 \mathrm{~N}$.

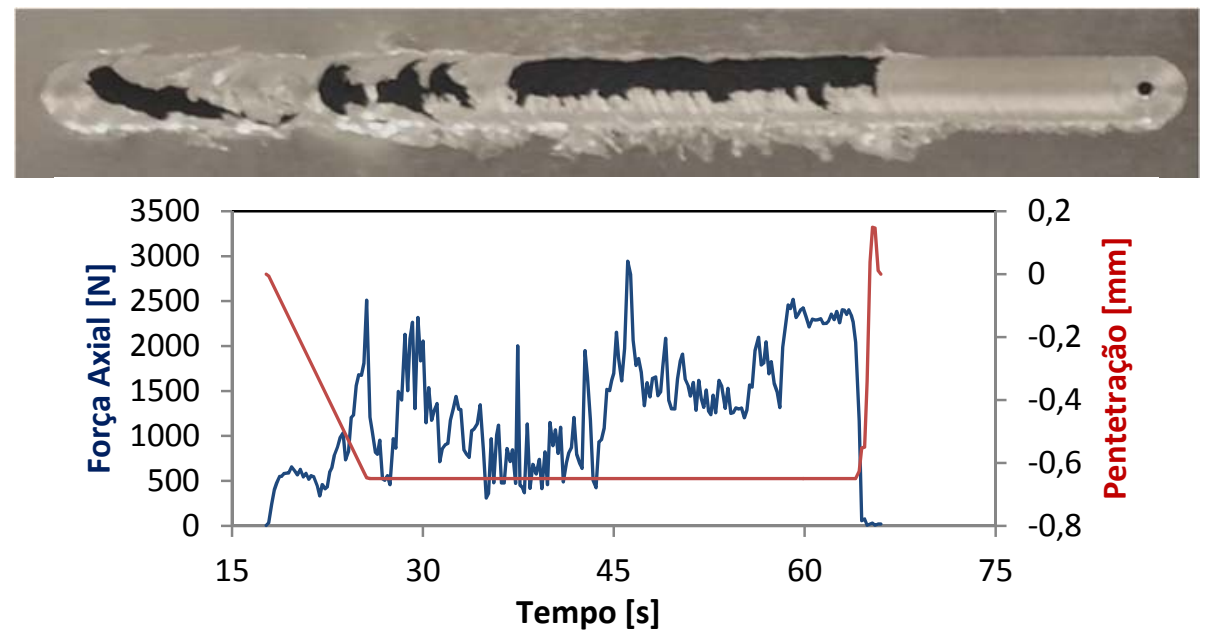

Figura 3. Teste 01 (Configuração 01 e Ferramenta 01).

A partir do resultado do Teste 01 , procurou-se ajustar os parâmetros do início da movimentação da ferramenta para que se obtivesse estabilidade de processamento do material em todo percurso. Entretanto, essa busca não foi bem sucedida, pois nos Testes 02 a 05 ocorreu o rompimento completo da chapa no percurso da ferramenta. Partindo-se para outra frente de trabalho, a ferramenta de soldagem foi substituída pela Ferramenta 02 (ombro com ranhuras espirais e pino facetado) e mudou-se para a Configuração 2 (duas chapas sobrepostas).

$O$ resultado de soldagem do Teste 06 , executado nessas novas condições, pode ser observado na Figura 4.

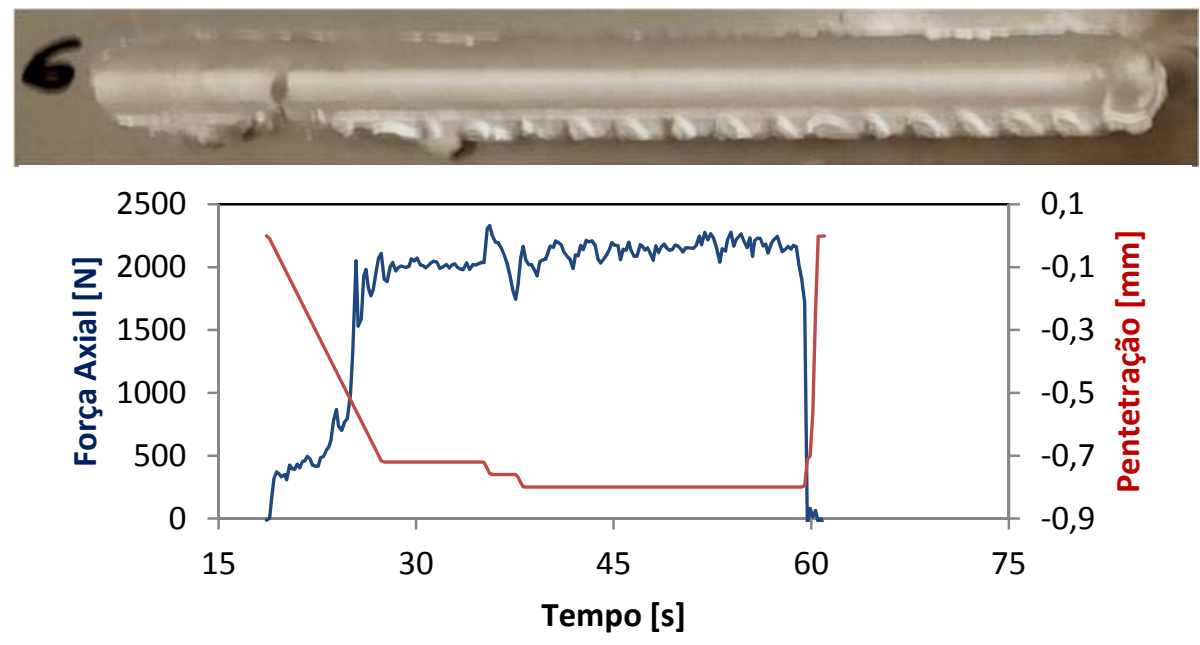

Figura 4. Teste 06 (Configuração 02 e Ferramenta 02).

Nota-se que foi obtida estabilidade de processamento das chapas, mesmo com uma pequena falha no trecho inicial, porém com rebarba excessiva. Observa-se que o controle de posição seguiu corretamente o parâmetro de penetração especificado, incluindo seus incrementos. A força axial flutuou de forma consistente entre 2000 e 
$2300 \mathrm{~N}$, apesar de existir alguma oscilação, principalmente nos instantes de incremento de penetração.

Em seguida, procurou-se ajustar os parâmetros de soldagem com a intensão de se diminuir a rebarba formada. Assim, foram realizados os Testes 07 a 09, destacandose os resultados desse último, em que o ângulo de ataque foi diminuído para $1^{\circ}$.

No Teste 09, conforme a Figura 5, houve alguma redução na formação de rebarbas. Entretanto, verifica-se que mesmo após os incrementos de penetração, ocorreu uma diminuição abrupta da força axial (entorno do instante $45 \mathrm{~s}$ ) sem que houvesse o rasgamento da chapa. Isso é um indício de que foram atingidas temperaturas demasiadamente altas, que diminuem a resistência do material à conformação durante seu processamento, e podem levar à baixa qualidade ou instabilidade do processo de soldagem.

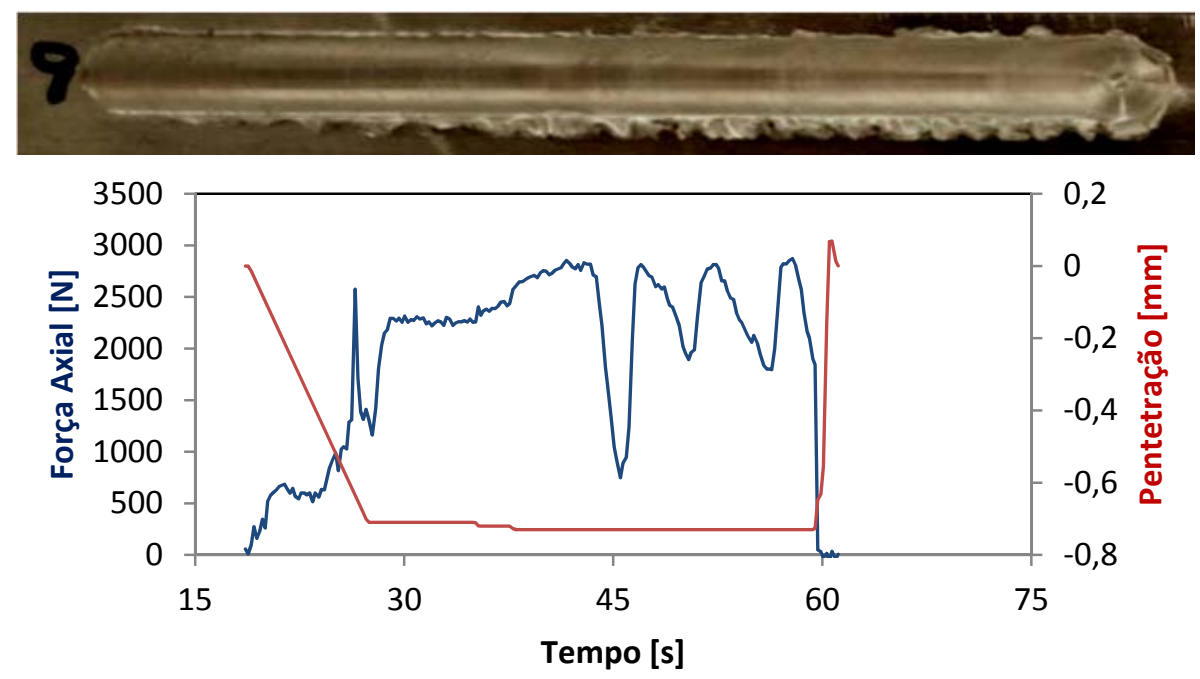

Figura 5. Teste 9 (Configuração 02 e Ferramenta 02).

Assim, com o intuito de diminuir o aporte térmico, foram realizados os Testes 10 a 12 em que se reduziu a velocidade de rotação de $1600 \mathrm{rpm}$ para $1200 \mathrm{rpm}$ e se aumentou a velocidade de avanço de $240 \mathrm{~mm} / \mathrm{min}$ para até $400 \mathrm{~mm} / \mathrm{min}$ (mantendose o ângulo de ataque de $1^{\circ}$ ). A Figuras 6 mostra os resultados do Teste 12 , em que foi utilizada velocidade de avanço de $400 \mathrm{~mm} / \mathrm{min}$.

Observa-se que o processo ficou estável mesmo com o aumento da velocidade de avanço. Exceto pela grande oscilação de força que ocorreu logo após o último incremento de penetração, a força axial flutuou de forma relativamente restrita na faixa de 2000 a $2500 \mathrm{~N}$.

Após esses resultados, alterou-se a configuração de soldagem para a união de chapas em topo com tira sobre as chapas (Configuração 3). Para o Teste 13, além da alteração da configuração, aumentou-se a velocidade de avanço para 500 $\mathrm{mm} / \mathrm{min}$. Porém o processo se instabilizou e levou à ruptura da tira. Nos Testes $14 \mathrm{e}$ 15 , a velocidade de avanço foi ajustada novamente para $400 \mathrm{~mm} / \mathrm{min}$. A única diferença entre esses testes residiu no fato de não terem sido utilizados incrementos progressivos de penetração no Teste 14. Apesar da única diferença teórica entre os Testes 14 e 15 ter sido a utilização ou não de incrementos progressivos de penetração, suspeita-se que alguma irregularidade geométrica das chapas de apenas $0,7 \mathrm{~mm}$ de espessura possa ter mascarado os resultados do Teste 14. Pois, no teste 15 , observou-se que houve duas falhas em relação a continuidade do material processado. 

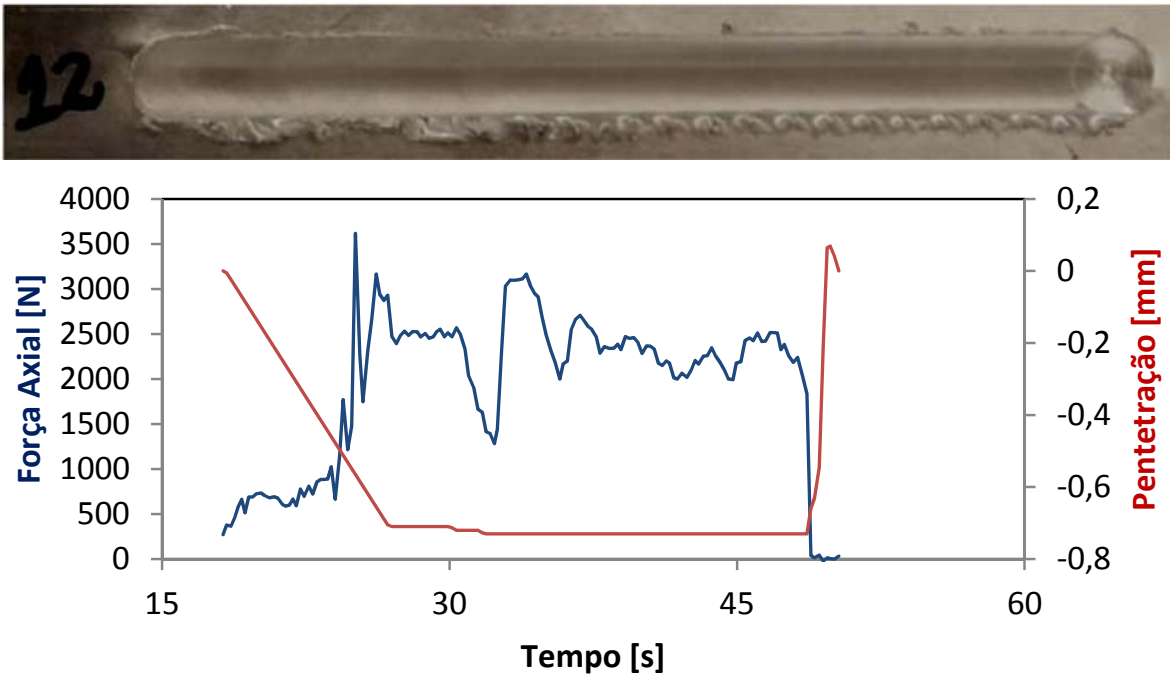

Figura 6. Teste 12 (Configuração 02 e Ferramenta 02).

Dessa forma, decidiu-se partir para o controle em modo de força, na expectativa de que eventuais irregularidades geométricas fossem automaticamente compensadas pela máquina de soldagem. Na Figura 7 pode ser observado os resultados do teste 16, realizado em controle de força de $2300 \mathrm{~N}$ (valor definido com base nos resultados do trecho estável obtidos na realização do Teste 15).

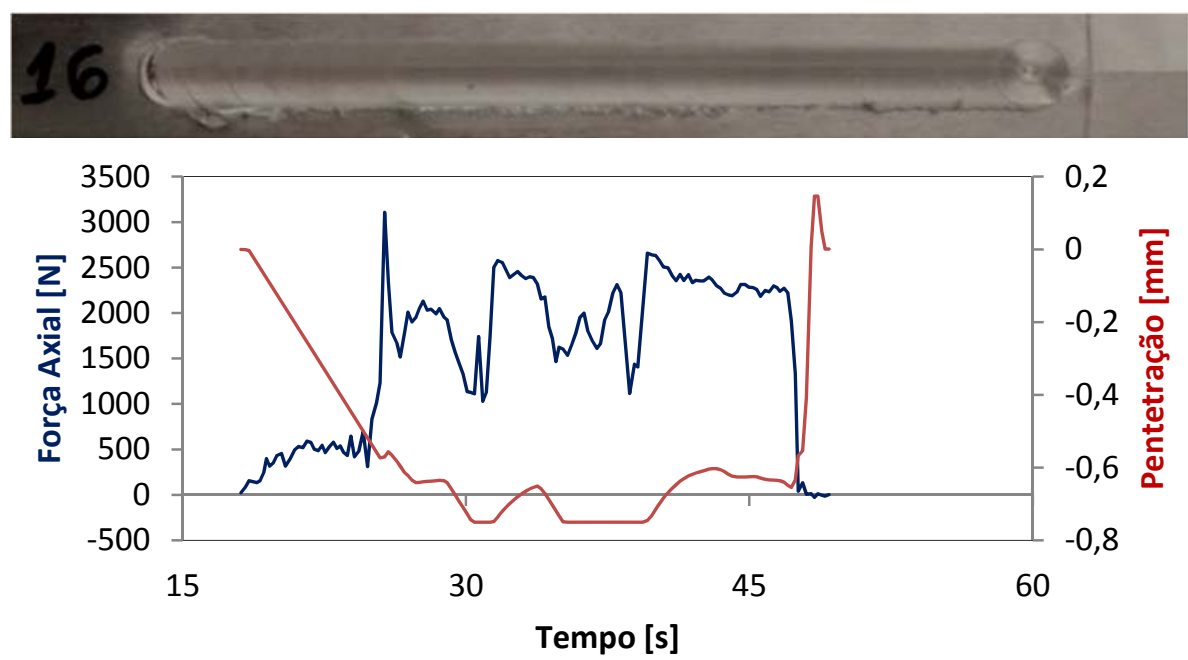

Figura 7. Teste 16 (Configuração 03 e Ferramenta 02).

Observa-se na Figura 7 que o processo manteve, ao menos superficialmente, a continuidade do material, e que houve menor formação de rebarbas, evidenciando significativa melhora ao se alterar o controle do modo de posição para o modo de força.

Também na Figura 7, nota-se que nos intervalos entre os instantes 30 e 32 s e 35 e $39 \mathrm{~s}$, houve redução da força (indicando diminuição da resistência do material à conformação durante seu processamento) e chaveamento automático do controle do modo de força para o modo de posição, baseado no parâmetro de penetração limite. Em função do bom aspecto visual, os mesmos parâmetros do Teste 16 foram utilizados para execução do Teste 17 , com a única diferença que foi obtido cordão 
de solda de maior comprimento. Mesmo após o processo entrar em regime, novamente ocorreu o chaveamento entre modo de controle por força e por posição na penetração limite. Assim, acredita-se que as diminuições momentâneas da resistência à conformação do material ao ser processado possam estar relacionadas a características locais do material como, por exemplo, heterogeneidade. Ressaltase ainda que, durante o controle de posição na penetração limite, as rebarbas ficaram maiores que no restante do cordão de solda.

No Teste 18, foi utilizada a Configuração 4 (tira sob as chapas em topo) e a ferramenta 3 (pino cilíndrico liso), e demais parâmetros similares aos do Teste 17. Como pode ser observado na Figura 8, apesar de ter sido configurado modo de controle por força de $2300 \mathrm{~N}$, a força não foi atingida com a mudança da ferramenta de soldagem e o controle foi automaticamente chaveado para o modo de posição na penetração limite. Além disso, foram identificadas pequenas cavidades superficiais ao longo do cordão de solda, provavelmente consequentes de uma baixa temperatura de processamento.

Assim, os testes seguintes foram configurados com controle de força a $1100 \mathrm{~N}$ e aumento de velocidade de rotação de $1200 \mathrm{rpm}$ para $1300 \mathrm{rpm}$ no Teste 19, e para 1400 rpm no Teste 20.

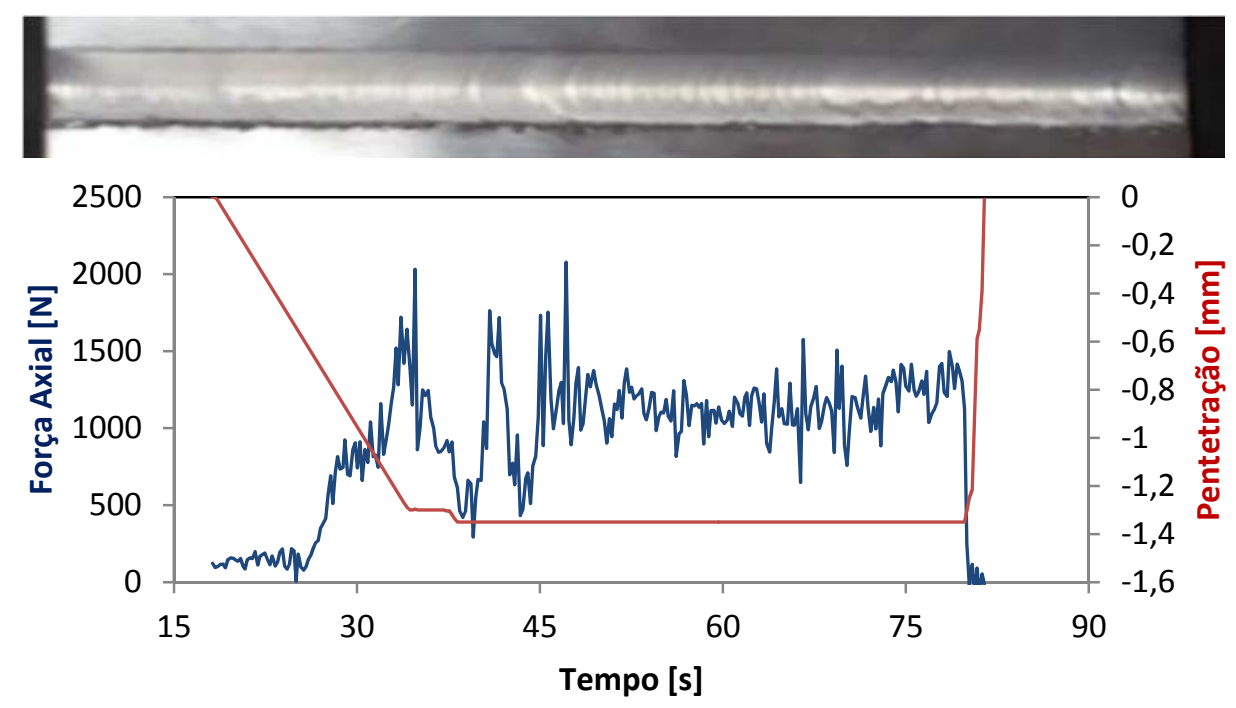

Figura 8. Teste 18 (Configuração 04 e Ferramenta 03).

No Teste 19, obteve-se efetivamente o controle por força a $1100 \mathrm{~N}$. Mas no Teste 20, o incremento na velocidade de rotação fez com que a resistência à conformação do material diminuísse a ponto do controle ser chaveado para modo de posição na penetração limite por quase todo o comprimento do cordão de solda. Em ambos os testes, permaneceram pequenas descontinuidades superficiais de material no cordão de solda.

Em seguida, o Teste 21 foi iniciado com a força axial diminuída de 1100 para $1000 \mathrm{~N}$ e mesma velocidade de rotação de $1400 \mathrm{rpm}$ do teste 20. Porém, esse teste foi abortado, pois houve penetração excessiva nas chapas a serem soldadas, provavelmente por configuração incorreta da superfície de soldagem na máquina.

No Teste 22, manteve-se a Configuração 4 (tira sob as chapas em topo), mas a ferramenta de soldagem foi alterada para a Ferramenta 4, com pino cônico liso. Os demais parâmetros foram idênticos aos do Teste 21. No Teste 22, a penetração inicial da ferramenta com pino cônico, consequência da força de $1000 \mathrm{~N}$ configurada, foi 
insuficiente para engajar o ombro de modo a propiciar suficiente geração de calor por atrito. Consequentemente, a penetração foi baixa durante quase todo o percurso da ferramenta e a soldagem foi irregular.

Para que fosse possível aumentar a penetração da ferramenta, dever-se-ia aumentar a força aplicada. Assim, diminuiu-se a velocidade de rotação de 1400 para $800 \mathrm{rpm}$ e aumentou-se a força axial de 1000 para $2300 \mathrm{~N}$ (prevendo-se que a diminuição da velocidade de rotação exigiria maior força axial) para execução do Teste 23. Entretanto, ocorreu o rasgamento completo das chapas ao longo do percurso da ferramenta. Assim, o Teste 24 foi realizado com parâmetros similares ao do Teste 22, exceto pela força axial que foi elevada para $1200 \mathrm{~N}$.

No teste 24 ocorreu penetração suficiente da ferramenta de soldagem e que se obteve uma solda contínua. Foram identificados ainda instantes em que o controle foi automaticamente chaveado para o modo de posição na penetração limite. Nesses instantes, houve maior formação de rebarba. Assim, o Teste 25 foi executado com a diminuição da intensidade do parâmetro de penetração limite de 1,35 para $-1,30 \mathrm{~mm}$.

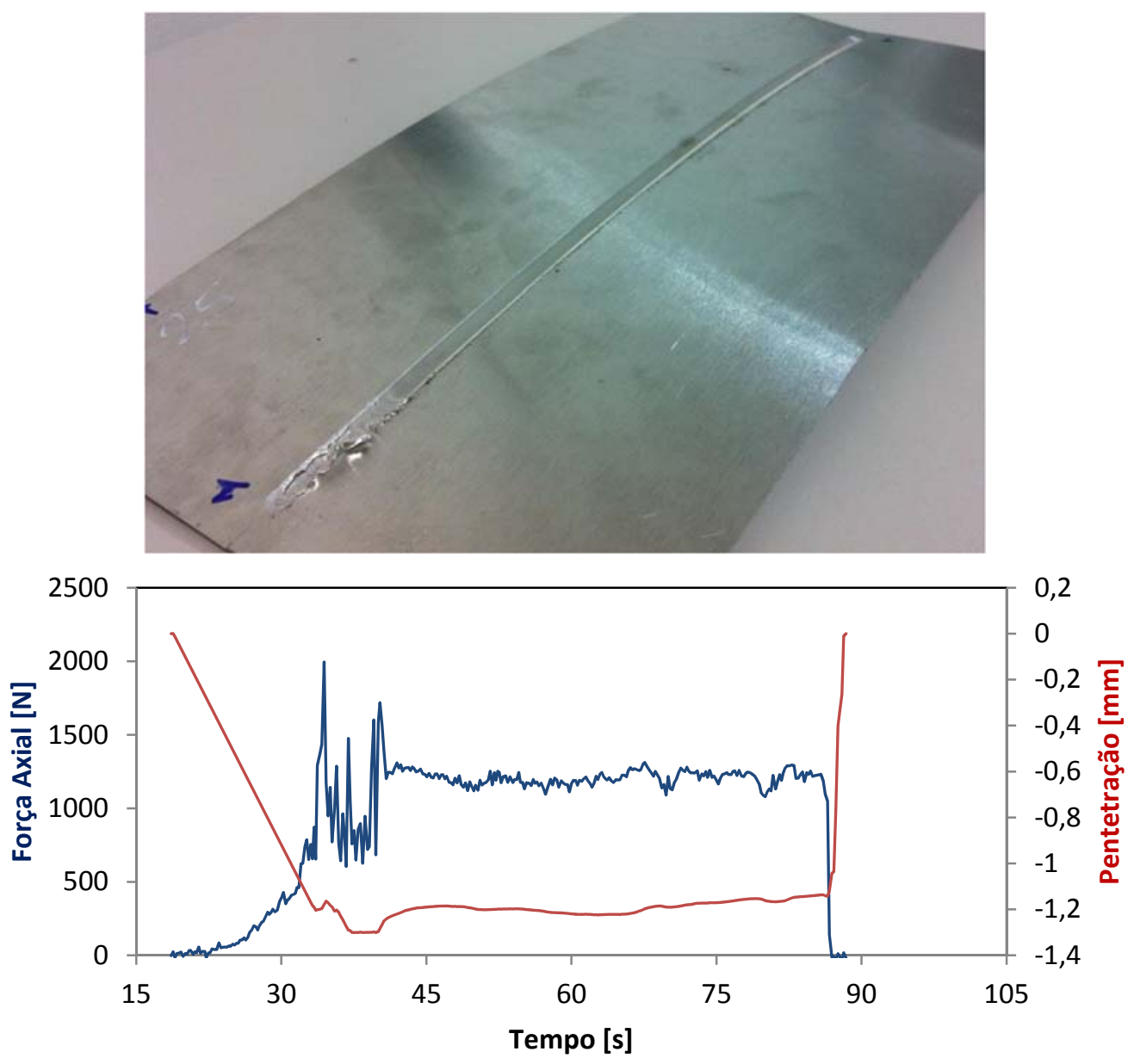

Figura 9. Teste 25 (Configuração 04 e Ferramenta 04).

Observa-se na Figura 9 que a solda apresentou bom aspecto visual (continuidade, pouca rebarba) em quase todo seu comprimento. Apenas no início não foi possível se obter estabilidade no processo de soldagem. Além disso, nota-se que ocorreu chaveamento do modo de controle de força para posição apenas no início da estabilização do processo de solda. 
Repetindo-se os parâmetros do Teste 25, foi executado o Teste 26. Apesar de terem sido utilizados os mesmos parâmetros do Teste 25, o acabamento das bordas das chapas processadas no Teste 26 apresenta qualidade inferior. Assim, a qualidade da soldagem variou conforme o contato entre materiais das chapas obtidos em cada trecho.

\section{CONCLUSÃO}

A execução dos testes permitiu a exploração inicial da aplicação do processo de soldagem por FSW à união de chapas de $0,7 \mathrm{~mm}$ de espessura, fabricadas na liga de alumínio 3105 H26. Além do simples ajuste de parâmetros de processo como velocidades de rotação, avanço, penetração e força axial, o aperfeiçoamento da soldagem foi consequência principalmente da identificação de que o modo de controle por força se mostrou mais adequado por possuir certa tolerância a irregularidades geométricas das chapas finas e que o acabamento do corte das chapas deve propiciar o maior contato possível entre os materiais das chapas a serem unidas.

Além disso, foi notado que, mesmo nos melhores resultados, houve chaveamento automático do controle em modo de força para o modo de posição baseado na penetração limite pré-definida. Isso indica que pequenos distúrbios no material fazem com que o processo saia de uma condição de regime uniforme. Ao mesmo tempo, mostra que a condição de regime é reestabelecida caso os parâmetros de processo sejam adequados.

Mesmo com os significativos avanços, não foi possível obter a mesma qualidade de soldagem ao longo de todo o cordão de solda. Notoriamente, no início da soldagem, não foi possível obter continuidade do cordão. Assim, sugere-se que o estágio transiente de início da soldagem seja especificamente abordado em trabalhos futuros. E ainda, acredita-se que deva ser investigada a soldagem de chapas em topo sem a inserção da tira sobreposta.

\section{Agradecimentos}

Agradeço a Votorantim Metais que proporcionou o desenvolvimento deste trabalho que agregou conhecimento e valores a minha carreira.

\section{REFERÊNCIAS}

$1 \quad$ Peel, M.; Steuwer, A.; Preuss, M.; Withers, P.J. Microstructure, mechanical properties and residual stresses as a function of welding speed in aluminium AA5083 friction stir welds. Acta Materialia Journal, 51, p. 4791-4801,2003.

2 Cruz, M. F.; Neto, C. M. Friction stir welding - review: potencial de aplicação na indústria aeroespacial. XI Simpósio de Aplicações Operacionais na Área de Defesa. São José dos Campos - SP. p. 6-10, 2009.

3 Rao, D.; Huber, K.; Heerens, J.; Santos, J. F.; HUBER, N. Asymmetric mechanical properties and tensile behaviour prediction of aluminium alloy 5083 friction stir welding joints. Materials Science \& Engineering A, 565. p. 44-50, 2013.

4 Patil, H. S.; Soman, N. S.; Effect of weld parameter on mechanical and metallurgical properties of dissimilar joints AA6082-AA6061 in T6 condition produced by FSW. Frattura ed Integrità Strutturale, 24. p.151-160, 2013. 